\title{
Properties of Mirror-surface Grinding for Metal Matrix Ceramic Composites
}

\author{
Tae-Soo Kwak ${ }^{\dagger}$
}

Department of Mechanical Engineering, Gyeongnam National University of Science and Technology, Gyeongnam 660-758, Korea

(Received October 20, 2011; Revised November 11, 2011, December 15, 2011; Accepted December 19, 2011)

\section{금속기지 세라믹 복합소재의 경면연삭 가공 특성 \\ 곽태수 $^{\dagger}$ \\ 경남과학기술대학교 기계공학과}

(2011년 10월 20일 접수; 2011년 11월 11일, 12월 15일 수정 ; 2011년 12월 19일 채택)

\begin{abstract}
This study has been focused on properties of mirror surface grinding technology by ELID(Electrolytic In-process Dressing) for metal matrix ceramic composites using in high precision mirror for optics. The experimental studies have been carried out to get mirror surface by grinding for composites, $\mathrm{Al}-\mathrm{SiC}, \mathrm{Al}$-graphite and $\mathrm{Mg}$-SiC. Grinding process is carried out with varying abrasive mesh type, depth of cut and feed rate using diamond wheel. The machining result of the surface roughness and condition of ground surface, have been analyzed by use of surface roughness tester and SEM measurement system. ELID grinding technology could be applied successfully for the mirror-surface manufacturing processes in spite of ductility of metal matrix material. As the results of experiments, surface roughness of $\mathrm{Al}-\mathrm{SiC}(45 \mathrm{wt} \%)$ has been the most superior in these experimental work-pieces as $0.021 \mu \mathrm{m}$ Ra.
\end{abstract}

Key words : Metal matrix ceramic composites, Grinding, Surface roughness, Al-SiC, Al-graphite, Mg-SiC

\section{1. 서 론}

금속기지 복합재료는 단일 금속재료에 비해 비강도, 비강 성 내열성 및 내구성이 우수할 뿐만 아니라 고분자기지 복합재료에 비해서도 내충격성 및 강성이 우수하며 고온 환경에서의 열적 안정성이 높아 자동차, 선박 및 항공우 주산업 분야에 이르기 까지 광범위한 응용이 기대되고 있 다. ${ }^{1)}$ 알루미늄이나 니켈 재질의 금속은 전 세계적으로 우 주/항공기계, 자동차, 토목/건축 및 전기/전자 분야에서 활용 되고 있으며, 향후 첨단산업 분야 기능성 부재로서 맞춤형 재료로 응용성이 매우 높다. 또한, 강도를 높이기 위해 세라 믹 재질을 첨가하여 금속기지 복합재료를 발포하는 방법도 적용되고 있다.

금속기지 세라믹 복합소재는 항공, 군사용, 첨단 산업에서 고기능성 부재로서 개발되고 있으나 혼합 재료의 경도차에 의해 가공성이 좋지 않으므로 고기능을 부여하기 위한 초정 밀 가공이 어렵다. 공구를 이용한 절삭가공에서는 복합소재 에 포함되어 있는 세라믹 입자의 크기에 따라 가공표면이 결정되는 경향이 있으며, 숫돌을 이용한 연삭가공은 기지

${ }^{\dagger}$ Corresponding author : Tae-Soo Kwak

E-mail : tskwak@gntech.ac.kr

Tel : +82-55-751-3371 Fax : +82-55-751-3319
금속의 비교적 높은 인성으로 인해 눈메움 현상이 심화되 므로 경면 가공을 하는데 어려움을 겪고 있다. 이러한 복 합소재의 초정밀 가공은 기존의 가공공정에 대한 데이터가 부족하므로 우수한 특성을 가진 세라믹 복합소재가 개발 되어도 가공 공정을 확립하는데 큰 어려움이 있다.

가공공정에 있어서 절삭성은 공구의 수명, 절삭에 소요 되는 동력, 재료 제거에 드는 비용, 표면조도 등을 기준으로 평가한다. ${ }^{2)}$ 난삭재는 먼저 소재의 높은 강도 및 경도로 인해 절삭 및 연삭 공구가 소재를 제거하지 못하는 것으로 알려져 있으며, 이 외에도 표면조도 및 형상정밀도에 대한 요구가 서브나노에서 나노미터 수준으로 높아짐에 따라 이에 대한 충족여부가 난삭재로의 채택 기준이 되고 있다. 금속기지 세라믹 복합소재는 절삭공구를 사용한 가공에 있어서는 절삭성이 세라믹의 함유량에 따라 크게 달라지 지만, 약 $30 \%$ 이하에서는 절삭가공이 가능하며 그 이상 에서는 절삭성이 급격하게 나빠진다. 이러한 경우에는 연삭 및 특수가공에 의해 표면가공을 해야 하며 전통적인 연삭 가공으로는 눈메움 현상이 심화되어 나노미터 수준으로 표면조도를 얻는 데는 한계가 있다. 따라서 금속기지 세라 믹 복합재료와 같이 표면조도 및 형상정밀도를 얻기 어려운 난삭재를 대상으로 보다 안전하고 가공효율이 높은 초정밀 부품생산에 있어서는 초미립 연삭숫돌에 의한 초정밀 경면 
연삭공정이 필요하다. 금속기지 세라믹 복합재료의 경우에 초미립 연삭숫돌을 이용한 연삭 가공에 있어서 가장 큰 문 제점은 눈메움(loading) 현상으로 인한 빈번한 드레싱에 있 다. 따라서 효율적인 가공을 위해서 적절한 드레싱 방법으 로 알려져 있는 ELID(Electrolytic In-Process Dressing) 연삭 법은 이에 대한 대안이 될 수 있다. ELID는 연속 전해드 레싱의 약자로 $\mathrm{CBN}$ 또는 다이아몬드와 같은 초경질 입자 를 갖는 숫돌을 연삭가공 중에 전해 방식으로 드레싱하는 기법이다. ELID 연삭법에 의한 연속 드레싱에서는 연삭과 드레싱이 병행되므로 연삭 숫돌의 눈메움 현상을 방지할 수 있는 장점이 있다. ${ }^{3)}$

본 연구는 특수 목적용으로 개발된 $\mathrm{Al}-\mathrm{SiC}, \mathrm{Al}$-graphite, $\mathrm{Mg}-\mathrm{SiC}$ 등 복합재료 시편에 대해서 평면연삭기를 활용하여 소재별 피가공 특성을 평가하고 복합재료의 응용성을 높이 기 위한 나노표면 가공 기술에 대한 기초데이터를 확보하고 자 한다. 또한, ELID 경면연삭 가공에 의한 피가공 특성을 평가하고 가공표면을 분석하여 광학부품에서 요구되는 형 상정밀도를 비교 분석한다.

\section{2. 실험 및 평가방법}

ELID 연삭가공은 주철을 결합재료로 한 도전성 연삭숫 돌과 펄스파형을 발생하는 전원장치, 비선형 전해현상을 동반하는 수용성 연삭액 등을 이용하여 가공 중 숫돌표 면에 산화피막을 형성시켜 다이아몬드 입자와 피가공물 간 의 피삭특성을 향상시키는 기술로서 나노 경면연삭에 활 용되고 있다.

연삭시에 피삭재는 소성변형에 의한 연성모드(ductile mode) 와 크랙의 생성 및 파단에 의한 취성모드(brittle mode)로 제거된다. Fig. 1은 연속 전해드레싱에 대한 개략적인 시스 템 구성도를 나타내고 있으며, Fig. 2는 ELID 연삭 사이클 을 보여주고 있다. ELID 사이클은 최초 전해 드레싱에 의해 일정 두께의 산화피막을 생성시키고 생성된 산화피막은 연

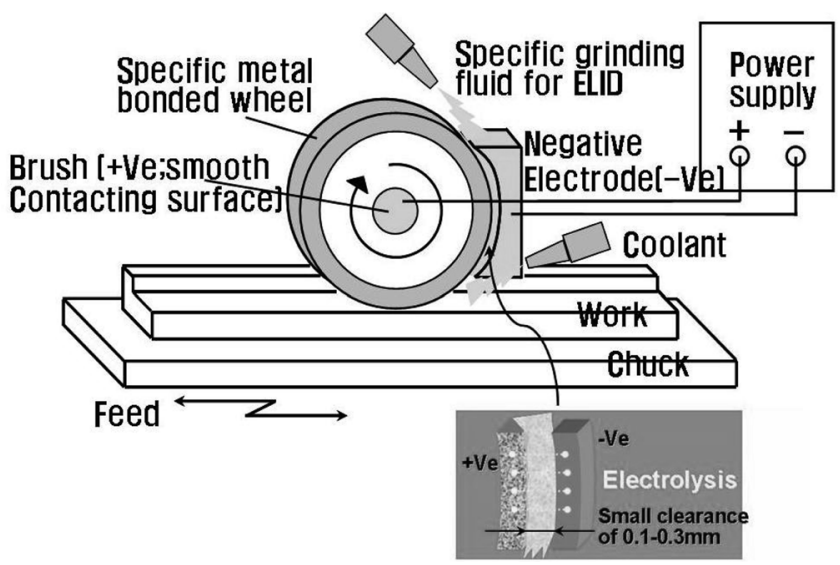

Fig. 1. Schematics diagram for ELID grinding system.

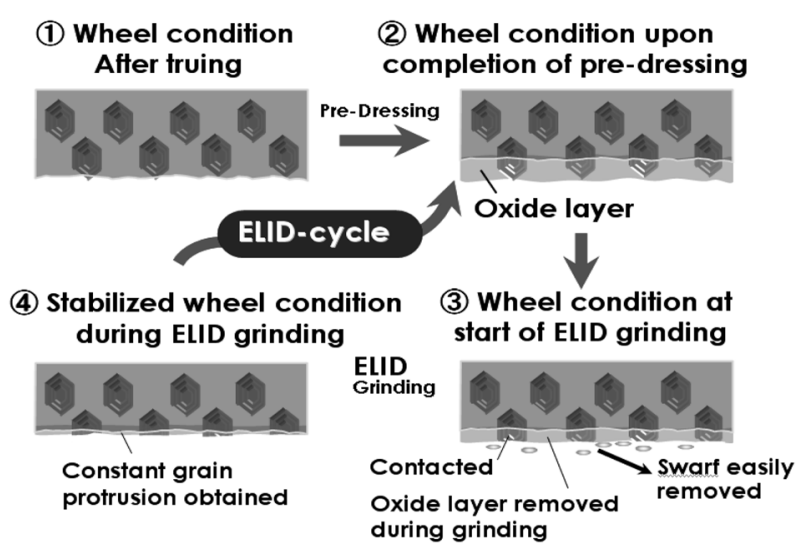

Fig. 2. Schematic diagram for ELID-cycle.

삭 가공 중에 연삭칩과 함께 배출되므로 탈락과 재생성 이 반복되는 것을 말한다.,5)

\section{1. 실험장치의 구성}

본 실험에 사용된 시편은 금속기지 복합재료로서 $\mathrm{Al}-\mathrm{SiC}$ (30 wt \%), Al-SiC(45 wt \%), Al-graphite, $\mathrm{Mg}-\mathrm{SiC}$ 이며 숫돌의 제원은 Table 1 과 같다. 연삭숫돌의 직경은 $150 \mathrm{~mm}$ 와 $160 \mathrm{~mm}$ 두 종류이며 숫돌 폭은 $10 \mathrm{~mm}$ 로 동일하다.

Fig. 3 은 ELID 경면연삭 실험장치의 구성을 나타낸 것이

Table 1. Specification of Experimental Equipments

\begin{tabular}{cc}
\hline Machine & YGS-63A \\
\hline Grinding wheel & Mesh No.:\#170, \#2000, \#4000, \#8000 \\
& Abrasive: Diamond \\
Bonding material: Cast iron \\
ELID Power supply & ED-910 \\
Grinding fluid & CG-7 \\
Workpiece & Al-SiC / Al-graphite / Mg-SiC \\
\hline
\end{tabular}

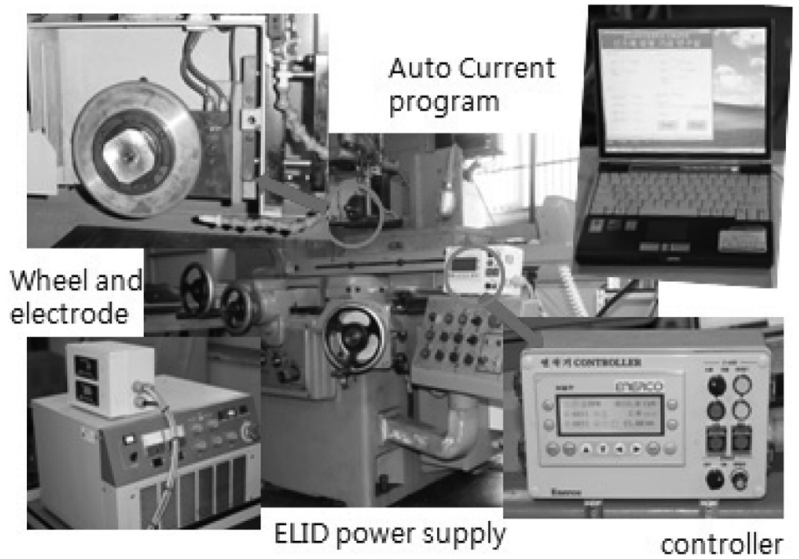

Fig. 3. Experimental system for ELID plane grinding. 
다. 장치는 범용 평면연삭기에 ELID 전원공급 장치를 연결 하고 연삭저항 및 ELID 전류의 흐름을 모니터링 할 수 있 도록 구성하였다. 연삭 가공시 숫돌의 저항과 $\mathrm{Z}$ 축의 저항을 측정하기 위해서 스핀들의 연삭저항과 $Z$ 축의 부하 전류값 을 출력하도록 프로그램을 구성하고, ELID 전원장치에서 나오는 입/출력 전류값을 동시에 출력 받아 연삭가공 중 ELID 전류 변화를 모니터링 하였다.

\section{2. 실험조건 및 측정}

연삭 실험은 숫돌의 지립이 큰 것부터 조밀한 순서로 연삭가공을 하였으며, 실험에서는 \#170에서 \#2000. \#4000, $\# 8000$ 의 순서로 하였다. 숫돌의 입도에 따른 연삭 조건은 Table 2 와 같다. 연삭 조건에서 전해 연속 전해드레싱을 위 한 전압과 전류의 조건은 모든 경우에 $70 \mathrm{~V}, 10 \mathrm{~A}$ 로 두었다.

또한 각 공정에서 연삭 개시 전 20-30분 정도 초기 전해 드레싱 하여 날 세우기를 하였고, 연삭이 끝난 뒤에 10-25분 간 숫돌을 공회전(spark out)시켜 가공물의 연삭면이 균일하 게 하였다. 시편이 완성되면 가공 표면조도(surface roughness) $(\mathrm{Ra}$ (평균 조도) 및 $\mathrm{Rmax}$ (최대 조도))를 측정하고 분석하 기 위해서 모바일 표면조도측정기(Diavite DH-6, Bowers Metrology, UK)와 표면조도측정기(SJ-400, Mitutoyo, Japan) 를 사용하였고, 표면의 피가공 특성 분석을 위해서 주사전 자현미경(SEM, JSM-5600LV, JEOL, Japan)을 이용하여 가 공후 시편의 표면 사진을 촬영하였다.

Table 2. Experimental Conditions for Surface Grinding

\begin{tabular}{ccccc}
\hline Mesh No. & $\begin{array}{c}\text { Depth of cut } \\
(\mu \mathrm{m})\end{array}$ & $\begin{array}{c}\text { Feed } \\
(\mathrm{mm})\end{array}$ & $\begin{array}{c}\text { Wheel speed } \\
(\mathrm{rpm})\end{array}$ & $\begin{array}{c}\text { Spark out } \\
(\mathrm{min} .)\end{array}$ \\
\hline$\# 170$ & 10 & 15 & 1800 & 10 \\
$\# 2000$ & 4 & 7 & 1800 & 20 \\
$\# 4000$ & 1 & 5 & 1800 & 20 \\
$\# 8000$ & 0.3 & 2 & 1800 & 20 \\
\hline
\end{tabular}

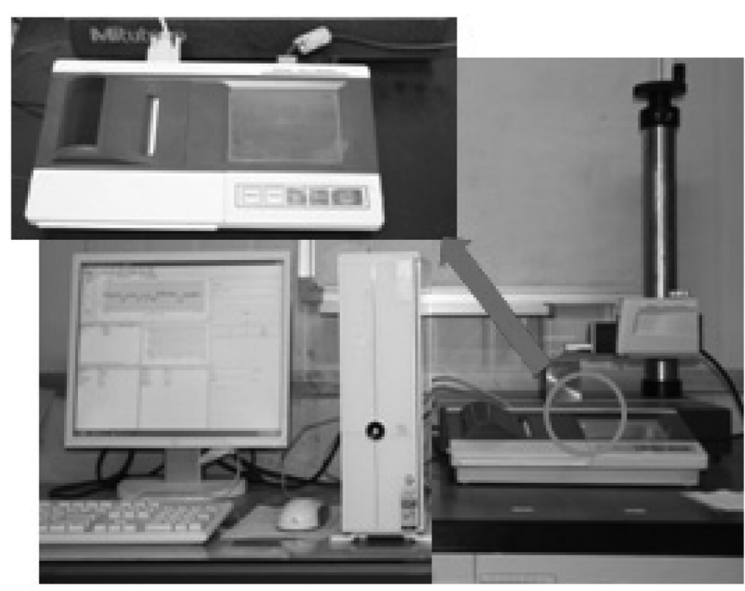

Fig. 4. Surface roughness tester(Mitutoyo SJ-400, Japan).

\section{3. 결과 및 고찰}

\section{1. 입도별 표면조도}

각 재료의 특성별로 숫돌입도와 표면조도의 관계를 시편 마다 중심부에서 둘레방향으로 총 3 번 측정하여 평균한 값을 비교하였다.

Fig. 5 는 $\mathrm{Al}-\mathrm{SiC}$ 의 $\mathrm{SiC}$ 함유량과 숫돌입도에 따른 표면 조도의 변화를 나타낸 것이다. 숫돌입도는 \#170부터 \#2000, $\# 4000, \# 8000$ 까지 실험하였으며 \#170일 때 표면조도 값이 $\mathrm{Al}-\mathrm{SiC}(30 \mathrm{wt} \%)$ 는 $0.12 \mu \mathrm{m} \mathrm{Ra}, \mathrm{Al}-\mathrm{SiC}(45 \mathrm{wt} \%)$ 는 $0.32 \mu \mathrm{m}$ Ra, \#2000일 때는 각각 $0.11 \mu \mathrm{m} \mathrm{Ra}, 0.07 \mu \mathrm{m} \mathrm{Ra}$ 로써 $\mathrm{Al}-\mathrm{SiC}$ (45 wt\%)는 숫돌의 입도가 \#170에서 \#2000으로 가공하였을 때 표면조도 값이 크게 개선되는 것을 알 수 있었다. \#4000 인 경우에는 각각 $0.12 \mu \mathrm{m} \mathrm{Ra}, 0.03 \mu \mathrm{m} \mathrm{Ra}$ 의 표면조도 값을 얻을 수 있었는데, $\mathrm{Al}-\mathrm{SiC}(45 \mathrm{wt} \%)$ 는 표면조도 값이 나아지 는 것을 확인 할 수 있었지만, $\mathrm{Al}-\mathrm{SiC}(30 \mathrm{wt} \%)$ 은 오히려 표 면정밀도의 변화는 관찰되지 않았다. \#8000에서 각각 $0.06 \mu \mathrm{m} \mathrm{Ra}, 0.02 \mu \mathrm{m} \mathrm{Ra}$ 로 표면조도가 가장 우수하게 얻 어졌으며 $\mathrm{SiC}$ 의 함유량이 $30 \mathrm{wt} \%$ 일 때보다 $45 \mathrm{wt} \%$ 일 경우 가 더욱 우수한 표면조도 값을 얻을 수 있었다.

Fig. 5 의 결과로부터 $\mathrm{SiC}$ 의 함유량이 $45 \mathrm{wt} \%$ 인 세라믹 복 합소재는 숫돌의 입도 변화에 비례하여 표면조도가 양호해 지는 것을 확인할 수 있었다. 반면에 $\mathrm{SiC}$ 의 함유량이 $30 \mathrm{wt} \%$ 인 세라믹 복합소재는 숫돌의 입도가 \#2000 및 \#4000에서 표면조도와의 상관성이 낮게 나타났는데 이것은 \#2000과 \#4000 입도의 숫돌에서 가공 중 눈메움 현상이 심화되기 때문인 것으로 사료된다.

Fig. 6 은 $\mathrm{Al}-\mathrm{SiC}(30 \mathrm{wt} \%)$ 와 Al-graphite의 표면조도 측정 결 과를 비교한 것이다. Al-graphite는 숫돌의 입도가 높아짐에 따라 표면조도는 향상되는 경향을 볼 수 있으나 가공조건에 따라 표면조도의 변화가 크게 나타났다. 즉, Ra 값이 \#170으 로 가공한 경우보다 \#2000으로 가공하였을 때 $0.36 \mu \mathrm{m} \mathrm{Ra}$ 로 더 높게 나타났으나 \#4000일 때는 $0.12 \mu \mathrm{m} \mathrm{Ra}$ 로 급격히 낮 아졌다. 또한 \#8000으로 가공하였을 경우에는 표면조도가 다시 높게 나타났다. 따라서 Al-graphite의 표면조도는 숫돌 입도와 무관하다고는 할 수 없으나 입도보다는 금속기지와
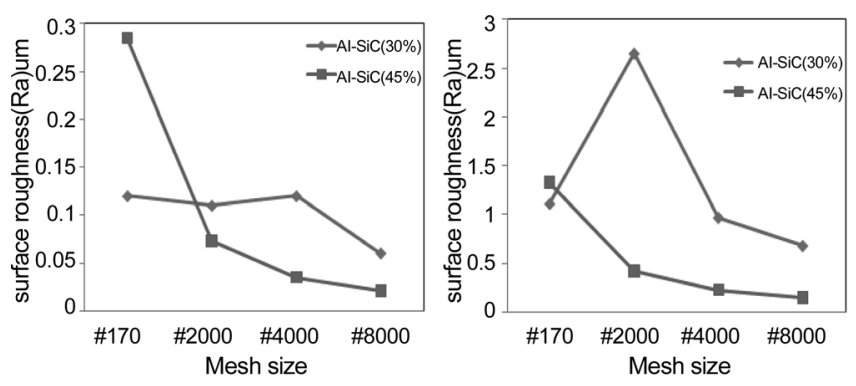

Fig. 5. Result of surface roughness of ELID ground surface of $\mathrm{Al}-\mathrm{SiC}(30 \mathrm{wt} \%), \mathrm{Al}-\mathrm{SiC}(45 \mathrm{wt} \%)$ materials. 

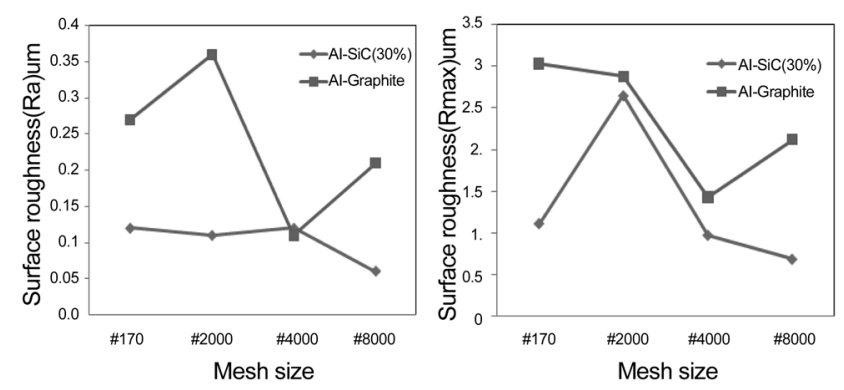

Fig. 6. Result of surface roughness of ELID ground surface of $\mathrm{Al}-\mathrm{SiC}(30 \mathrm{wt} \%)$, Al-graphite composites.

세라믹의 결합상태의 영향을 크게 받는 것으로 사료된다. 한편, $\mathrm{Mg}-\mathrm{SiC}$ 에 대해서는 Fig. 7과 같이 ELID 연삭 가공 후에 Ra와 Rmax 값은 입도와 무관하게 나타나는 것을 알 수 있다. ELID 연삭은 습식가공으로 연속적으로 수산화이 온을 함유한 연삭액을 공급하므로 마그네슘이 물과 반응하 여 숫돌의 입도보다는 연삭액과 시편과의 접촉시간에 따 라 표면조도가 영향을 받는 것으로 생각된다.

Fig. 7에서 \#4000과 \#8000 숫돌의 경우 표면조도가 높 아졌다가 다시 낮아지는 것을 볼 수 있는데 이와 같이 미세 지립의 숫돌을 사용하는 경우 1 회 절입량은 $1 \mu \mathrm{m}$ 이하로 매우 작고 가공시간은 길어지기 때문에 표면조도가 나빠 지는 것으로 생각된다.

Fig. 8은 각 시편을 측정한 표면조도 결과를 입도별로 $\mathrm{Ra}$ 및 $\mathrm{Rmax}$ 값을 비교한 것이다. 전체적으로 $\mathrm{Al}-\mathrm{SiC}(45 \mathrm{wt} \%)$
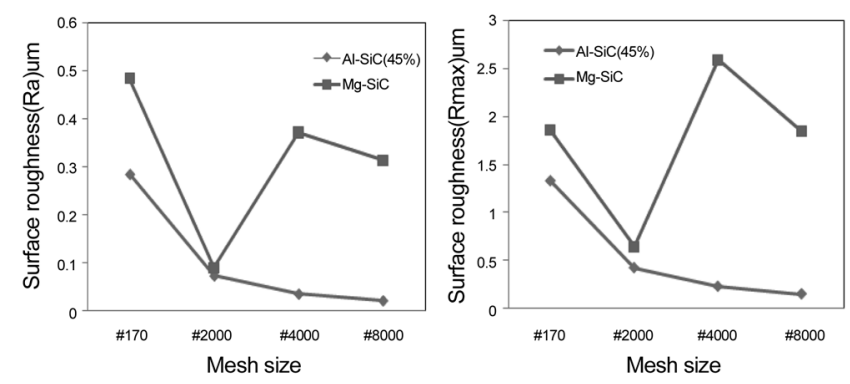

Fig. 7. Result of surface roughness of ELID ground surface of $\mathrm{Al}-\mathrm{SiC}(45 \%), \mathrm{Mg}-\mathrm{SiC}$ materials.
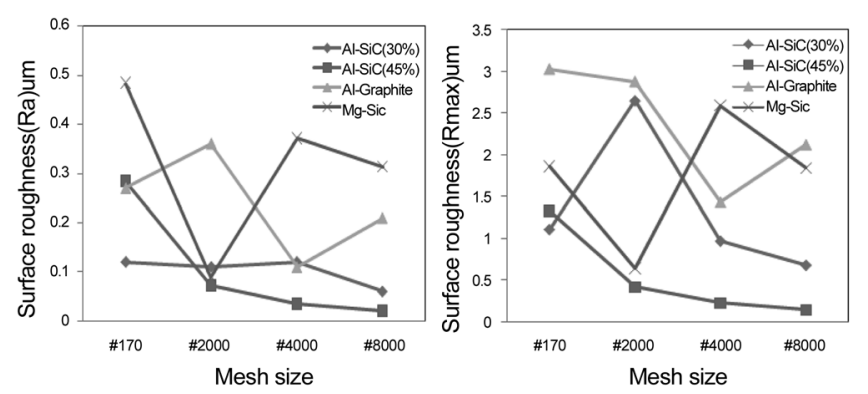

Fig. 8. Result of surface roughness of ELID ground surface of metal matrix ceramic composites.
의 경우가 가장 높은 정밀도를 보였으며 $\mathrm{Al}-\mathrm{SiC}(30 \mathrm{wt} \%)$ 의 경우 $\mathrm{Al}-\mathrm{SiC}(45 \mathrm{wt} \%)$ 에 비해 표면조도 값에 차이는 있지만 다른 시편에 비해 높은 정밀도를 나타내었다. Al-graphite와 $\mathrm{Mg}-\mathrm{SiC}$ 는 숫돌의 입도와 표면조도와의 상관성은 적었으 며, 가공조건 외적인 요인과 관계가 있는 것으로 보인다. Table 3은 접촉식 표면조도 측정기로 측정한 데이터이다.

\section{2. 가공표면 특성 분석}

Fig 9는 \#4000 숫돌을 이용한 경면 연삭 후 표면의 SEM 사진을 찍은 것이다. $\mathrm{Al}-\mathrm{SiC}(45 \mathrm{wt} \%)$ 의 경우 $\mathrm{Al}-\mathrm{SiC}(30 \mathrm{wt} \%)$ 에 비해 가공표면이 매우 우수한 것을 확인할 수 있으며, $\mathrm{Al}-\mathrm{SiC}(30 \mathrm{wt} \%)$ 의 표면은 알루미늄 함유량이 높아 $\mathrm{Al}-\mathrm{SiC}$ (45 wt\%)에 비해 비교적 많은 연삭 버(burr)가 가공 표면에 붙어있는 것을 알 수 있다. 또한 Al-graphite의 경우에는 가공표면에 섬유상의 graphite 입자가 탈락된 것을 확인할 수 있었다. $\mathrm{Mg}-\mathrm{SiC}$ 의 경우에는 가공표면에 연삭 흔적이 나 타나지 않는데 이것은 마그네슘이 연삭액의 수산화이온과 다음과 같이 반응하여 연삭흔적이 가공 중에 지워지는 것으 로 생각된다.

$$
\mathrm{Mg}+2 \mathrm{H}_{2} \mathrm{O} \rightarrow \mathrm{Mg}(\mathrm{OH})_{2}+\mathrm{H}_{2}
$$

Table 3. Measurement Results on the ELID Ground Surface

\begin{tabular}{|c|c|c|c|c|c|c|c|c|}
\hline \multirow{2}{*}{ Materials } & \multicolumn{2}{|c|}{ \#170 } & \multicolumn{2}{|c|}{$\# 2000$} & \multicolumn{2}{|c|}{$\# 4000$} & \multicolumn{2}{|c|}{$\# 8000$} \\
\hline & $\begin{array}{c}\mu \mathrm{m} \\
\mathrm{R}_{\mathrm{a}}\end{array}$ & $\begin{array}{c}\mu \mathrm{m} \\
\mathrm{R}_{\max }\end{array}$ & $\begin{array}{c}\mu \mathrm{m} \\
\mathrm{R}_{\mathrm{a}}\end{array}$ & $\begin{array}{c}\mu \mathrm{m} \\
\mathrm{R}_{\max }\end{array}$ & $\begin{array}{c}\mu \mathrm{m} \\
\mathrm{R}_{\mathrm{a}}\end{array}$ & $\begin{array}{c}\mu \mathrm{m} \\
\mathrm{R}_{\max }\end{array}$ & $\begin{array}{c}\mu \mathrm{m} \\
\mathrm{R}_{\mathrm{a}}\end{array}$ & $\begin{array}{c}\mu \mathrm{m} \\
\mathrm{R}_{\max }\end{array}$ \\
\hline $\begin{array}{c}\mathrm{Al}-\mathrm{SiC} \\
(30 \mathrm{wt} \%)\end{array}$ & 0.12 & 1.11 & 0.11 & 2.65 & 0.12 & 0.97 & 0.06 & 0.68 \\
\hline $\begin{array}{c}\text { Al-SiC } \\
(45 w t \%)\end{array}$ & 0.32 & 1.32 & 0.07 & 0.42 & 0.03 & 0.22 & 0.02 & 0.14 \\
\hline Al-Graphite & 0.27 & 3.03 & 0.36 & 2.88 & 0.11 & 1.43 & 0.21 & 2.12 \\
\hline Mg-SiC & 0.57 & 1.86 & 0.08 & 0.64 & 0.37 & 2.59 & 0.31 & 1.84 \\
\hline
\end{tabular}

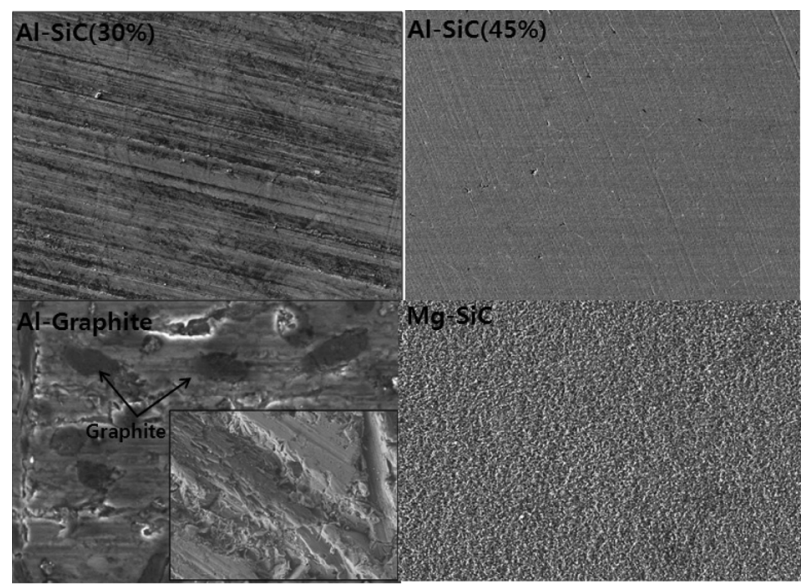

Fig. 9. SEM pictures of ELID ground surface using $\# 4000$ grinding wheel. 
$\mathrm{Mg}-\mathrm{SiC}$ 의 경우에는 습식 공정보다 건식 공정에서 가공 하는 것이 적합하다.

\section{4. 결 론}

본 연구는 금속기지 세라믹 복합재료 시편에 대해서 범 용평면연삭기를 활용하여 ELID 경면연삭 가공하고 가공 표면의 피가공 특성을 분석한 결과 다음과 같은 결론을 얻었다.

1. 세라믹 복합재료 시편에 대해서 동일한 가공조건으로 ELID 경면연삭 실험한 결과 $\mathrm{Al}-\mathrm{SiC}(45 \mathrm{wt} \%)$ 의 경우에 $0.021 \mu \mathrm{m} \mathrm{Ra}$ 로 가장 우수한 표면조도를 얻을 수 있었다. $\mathrm{SiC}$ 의 함유량이 낮으면 기지 금속의 인성에 의한 눈메움 현상 이 심화되었다.

2. 주사전자현미경을 이용하여 가공표면을 분석한 결과, Al-graphite는 가공 중에 섬유상의 graphite 입자가 탈락하고 있는 것을 확인할 수 있었다.

3. $\mathrm{Mg}-\mathrm{SiC}$ 는 마그네슘과 연삭액의 수산화 이온이 반응
하여 연삭흔적이 지워지는 현상이 나타났으며, 이것은 연 삭액과 접촉하고 있는 시간이 피가공 표면의 표면조도에 영향을 미치는 것을 확인 할 수 있었다.

\section{REFERENCES}

1. M. Kang, M. Lee, and J. Lee, "Evaluation of Thermal Shock Damage of Metal Matrix Composite Using Ultrasonics," $J$. Kor. Soc. Mech. Eng., 29 [11] 1480-87 (2005).

2. S. Cheon, "Tensile Behaviour of Foamed Metal Matrix Composite Using Stochastic FE Model," J. Kor. Soc. Comp. Mater., 17 [2] 34-9 (2004).

3. Y. Kim, T. Kwak, and K. Kim, "Mirror-surface Machining Properties of Structural Ceramics using Diamond Abrasives," $J$. Kor. Ceram. Soc., 47 [4] 290-95 (2010).

4. T. Kwak and H. Ohmori, "Nano-level Mirror Surface Machining Technology for SiC Ceramics Mirror," J. Kor. Soc. Prec. Eng., 23 [6] 29-36 (2006).

5. T. Kwak, "Machining Properties to Nano-Level Mirror Surface Finishing for Fine Grained WC-Co 18\% Alloy using Magnetic Polishing Slurry," J. Kor. Ceram. Soc., 46 [1] 102-7 (2009). 